\title{
Adhesion Testing of Printed Inks While Varying the Surface Treatment of Polymer Substrates
}

\author{
Clayton Neff
}

Edwin Elston

Amanda Schrand

Nathan B. Crane

Brigham Young University - Provo, nbcrane@byu.edu

Follow this and additional works at: https://scholarsarchive.byu.edu/facpub

Part of the Manufacturing Commons, and the Other Mechanical Engineering Commons

\section{Original Publication Citation}

Clayton Neff, Edwin Elston, Amanda Schrand, and Nathan B. Crane, "Adhesion Testing of Printed Inks while Varying the Surface Treatment of Polymer Substrates," The Journal of Adhesion, DOI: 10.1080/00218464.2019.1668782, Published 9/21/2019.

\section{BYU ScholarsArchive Citation}

Neff, Clayton; Elston, Edwin; Schrand, Amanda; and Crane, Nathan B., "Adhesion Testing of Printed Inks While Varying the Surface Treatment of Polymer Substrates" (2019). Faculty Publications. 5341. https://scholarsarchive.byu.edu/facpub/5341 accepted for inclusion in Faculty Publications by an authorized administrator of BYU ScholarsArchive. For more information, please contact ellen_amatangelo@byu.edu. 


\title{
ADHESION TESTING OF PRINTED INKS WHILE VARYING THE SURFACE TREATMENT OF POLYMER SUBSTRATES
}

\author{
Clayton Neff ${ }^{1}$, Edwin Elston ${ }^{1}$, Amanda Schrand ${ }^{1}$, Nathan Crane ${ }^{2}$ \\ Corresponding author: Clayton Neff \\ Email: claytonneff@mail.usf.edu \\ ${ }^{1}$ Air Force Research Laboratory, Fuzes Branch, Munitions Directorate, Eglin AFB, FL \\ ${ }^{2}$ Mechanical Engineering Department, Brigham Young University, Provo, UT
}

\begin{abstract}
Additive manufacturing with conductive materials enables new approaches to printed electronics that are unachievable by standard electronics manufacturing processes. In particular, electronics can be embedded directly into structural components in nearly arbitrary 3D space. While these methods incorporate many of the same materials, the new processing methods require standard test methods to compare materials, processing conditions, and determine design limits. This work demonstrates a test method to quantitatively measure the adhesion failure of printed inks deposited on a substrate without changing the ink printing conditions. The proposed method is an adaption of single lap shear testing in which the lap joint is created by bonding the second substrate to the ink after curing. It was found that the interfacial shear strengths are independent of the adhesives used to attach cured conductive ink to the second substrate. In addition, chemical surface treatments of flame and plasma and mechanical sand-blasting increase the interfacial shear strengths by $\sim 25 \%$ and $80 \%$, respectively while altering the adhesive failure mode to cohesive failure for most cases. This work also shows extruded substrates with undulated features increase adhesion strength; therefore, in addition to surface treatments, the geometric freedom of additive manufacturing (AM) could be leveraged to design surface features for enhanced adhesion.
\end{abstract}


Keywords: additive manufacturing, adhesion, conductive inks, printed electronics, single lap shear testing, surface treatments,

\section{Introduction}

The additive manufacturing (AM) of single material systems (i.e. polymers, metals) has matured in understanding to the point that AM is competitive with traditional methods for low volume manufacturing [1-4]. Interest is growing in the hybridization of traditional and AM processes to create multi-material functional electronics. Published work has demonstrated fabrication of a variety of 3D systems with embedded sensing, actuation, power storage, and control [5-8]. However, there are many challenges to overcome before enabling the implementation of these integrated systems, particularly to provide the reliability required for applications in defense and other demanding sectors [9].

One challenge includes a critical need for part testing and qualification procedures that consider both electronic performance and functionality in harsh environmental conditions such as temperature/humidity extremes, vibration, and shock [10] to support design and validation of systems with embedded electronics. In a prior work, a robust 3D printed planar patch antenna was designed and demonstrated was survive under harsh environmental conditions [11]. In the prior work, a correlation was found between adhesion and RF performance under extreme environmental loads. When applying accelerations up to 20,000 g's and thermal cycling between 70 and $-55^{\circ} \mathrm{C}$, radio frequency $(\mathrm{RF})$ performance was compromised if adhesion was not maintained [11]. However, there are limited methods available for quantitatively measuring the adhesion of printed inks to assure adequate system function.

Printed systems with integrated functionality require depositing dissimilar layers, including additional structural materials, on top of electronic features. The interlayer bond strength is critical to understanding the load bearing capability, and fracture characteristics of these 3D 
systems. However, current techniques are not well-suited for evaluating the interfacial strengths of the printed inks because the inks are applied and cured like a coating but then become the substrate for subsequent layers. The adhesion of the ink to the deposition substrate could be examined with coating adhesion tests like scotch tape testing and cross-hatch scratch testing, but these only provide qualitative adhesion indications, which makes effective comparisons difficult [12-14]. For example, Figure 1 shows the results of cross-hatch scratch testing of conductive inks with different surface treatments are indistinguishable.

The goal of this work is to evaluate a modified single lap shear testing process as a quantitative evaluation of adhesion of conductive inks to the substrate on which they are deposited.

Therefore, single lap shear strength of samples with varying surface treatments was measured to quantify the impact of surface treatments and inform mechanical design criteria since prior work shows surface treatments can enhance the mechanical strength of bonded joints $[15,16]$.The single lap shear tests show how surface treatments can enhance the interfacial shear strength and alter adhesive failure modes of conductive inks in order to increase the resilience of printed electronic systems subjected to harsh environments. This method could also be used to measure the adhesion of the ink to a subsequent layer deposited on top of the ink in future work.

\section{Methods and Materials}

Single lap shear testing is typically used to measure the bond strength of an adhesive connecting two overlapping substrates. Single lap shear testing provides a quantitative adhesion measurement to compare substrate materials, surface treatments, and determine design limits. A similar capability for printed and cured inks would advance design and qualification of printed electronics. Typically, printed inks are deposited and then cured before depositing additional layers. If the ink is simply substituted for adhesive in the traditional single lap shear testing 
process, its curing process is altered and the resulting measurements may not be indicative of typical use cases. Therefore, the ink was deposited and cured on one substrate using a standard cure profile and then the second substrate is bonded on top with an adhesive (Figure 2) as opposed to 'sandwiching' the ink between overlapping substrates. The adhesive used to attach the top substrate to the coating (printed ink in this work) should have the following properties:

(1) greater adhesion strength to the top substrate than the adhesion strength of the printed ink/substrate interface,

(2) stronger adhesion to the printed ink than the adhesion of the printed ink/substrate interface,

(3) negligible impact on the properties of the printed ink/substrate interface [17].

\section{Single Lap Shear Fabrication and Testing}

Figure $2 \mathrm{a}$ and $2 \mathrm{~b}$ show a machined fixture that was designed to process five multi-material shear test samples with reproducible alignment and bond thicknesses. Slots maintain alignment and prevent rotation while the adhesive is curing and a machined step sets the thickness of the conductive ink and adhesive layer.

Single lap shear samples were fabricated by using a simple spreading system (Figure 2c) that used a blade to spread $12.7 \mathrm{~mm}$ of conductive ink at a thickness of $50 \mu \mathrm{m}$ and speed of 1.67 $\mathrm{mm} / \mathrm{s}$ on one end of the substrate repeatedly. A thickness of $50 \mu \mathrm{m}$ was chosen for conductive ink as it is within the range of printed electronic thicknesses with direct write nozzle dispensing methods. Once the conductive ink was spread it was cured at $80^{\circ} \mathrm{C}$ for one hour. Next, an adhesive is spread with the same parameters as the conductive ink but with a thickness of $75 \mu \mathrm{m}$ on a free substrate in order to bond the cured conductive ink to the top single lap shear substrate. The substrates with the spread adhesive layer are placed into the bottom wells of the 
machined fixture from Figure $2 \mathrm{a}$ and $2 \mathrm{~b}$ before mating the substrates with cured conductive ink. A weight is then placed on the top substrates to apply uniform pressure and to compress the 75 $\mu \mathrm{m}$ of adhesive to the designed thickness of $50 \mu \mathrm{m}$ for uniform coverage while curing of the adhesive transpires. The batch of five single lap shear samples per sample type were tested in a tensile tester 24 hours after fabrication.

Single lap shear testing was performed in accordance to ASTM D 3163 [18] but sample geometry was scaled from adherend length of $100 \mathrm{~mm}$ (4”) and width of $25.4 \mathrm{~mm}$ (1") to a length of $50.29 \mathrm{~mm}\left(1.98^{\prime \prime}\right)$ and width of $12.19 \mathrm{~mm}\left(0.48^{\prime \prime}\right)$ to reduce material usage. An MTS 858 Tabletop system was used for shear testing the samples with a loading rate of $1 \mathrm{~mm} / \mathrm{min}$. Spacers with a thickness of $1 / 16$ inch were used to eliminate bending due to the offset between the two substrates as seen in Figure 2d.

Single lap shear testing reveals the interface failure modes of bonded systems. Figure 3 depicts the adhesive failure modes for interlayer bonding considered in this work. Adhesive failure denotes adhesive de-bonding between the polymer substrate and ink that indicates weak bonding of the ink and is generally least preferred. Cohesive failure denotes the conductive ink adheres strongly to the substrate and failure occurs due to internal ink separation. Cohesive failure is often the preferred failure mode as a strong bond of the ink is evident. Mixed failure mode consists of both cohesive and adhesive failure modes while substrate failure denotes the bond of the ink is stronger than the fracture strength of the substrate.

\section{Materials}

In order to make the method readily accessible for replication in other laboratories, we used the common polymer acrylonitrile-butadiene-styrene (ABS) as the substrate material and a commercially available silver conductive ink, CB028, by DuPont. ABS coupons $(50.29 \mathrm{~mm}$ x 
$12.19 \mathrm{~mm})$ were laser cut from $1.59 \mathrm{~mm}(1 / 16 ”)$ sheets (McMaster-Carr \#8586K151). The ABS sheets had different surface finish on the opposite sides of the ABS, a gloss and a matte surface finish. The gloss side of the ABS was utilized for all testing unless otherwise noted. After laser cutting and deburring of any built up edge, all samples were sonicated at $20 \mathrm{kHz}$ for eight minutes in $60 \mathrm{~mL}$ isopropyl alcohol (IPA) and $40 \mathrm{~mL}$ deionized water (DI) water.

Printed ABS single lap shear substrates were additively manufactured with the same dimensions of the laser cut smooth ABS sheet single lap shear substrates to compare the adhesion of conductive ink to printed substrates versus smooth untreated substrates. The substrates were printed with the fused deposition modelling extrusion process on an nScrypt 3Dn Table Top system with $100 \mu \mathrm{m}$ layer heights. Extruded printed substrates have inherent undulated surface roughness from the deposition of individual extrusion roads; which results in anisotropic material properties dependent on extrusion orientation $[19,20]$. Therefore, substrates were printed with both perpendicular and parallel extrusions relative to the long axis of the single lap shear substrates to evaluate if adhesion is dependent on the undulated extrusion orientation as illustrated in Figure 4.

DuPont CB028 silver conductive ink was mixed in a Thinky ARE-310 planetary centrifugal mixer for at least four minutes at $1000 \mathrm{RPM}$ prior to ink spreading and cured for 1 hour at $80^{\circ} \mathrm{C}$. Two adhesives were utilized in this work. The first was Pelco epoxy, which is a two-part epoxy mixed with a 2:1 ratio of resin (product \#813-502) to hardener (product \#813-515). The epoxy mixture was degassed in a vacuum chamber for 15 minutes after mixing by hand for one minute to reduce outgassing during curing. The epoxy cured at room temperature $\left(23^{\circ} \mathrm{C}\right)$ for 24 hours. The other adhesive was Bazic Superglue (cyanoacrylate). Note: the cyanoacrylate samples were 
fabricated individually in the fabrication procedures instead of in a set of 5 since the cyanoacrylate set quickly.

\section{Surface Treatments}

The impact of three surface treatments on contact angle and single lap shear strength were measured. The treatments were: plasma, flame, and sand-blasting. These surface treatments were selected because they increased the shear bond strength and altered the adhesive failure mode of dental cements and other coatings [21-26].

- Untreated: no treatment other than IPA wiped one hour prior to fabrication or contact angle measurement.

- Sand-blasted: 50/60 grit, $120 \mathrm{psi}, 2$ inches from blaster to substrate, exposure time $\sim 10$ seconds. The sand-blasted samples were again sonicated in $60 \mathrm{~mL}$ IPA and $40 \mathrm{~mL}$ DI water for eight minutes after blasting to remove any debris.

- Flame: Dremel micro-pen torch mounted in a 3D motion system. The treating distance and traverse speed were varied to optimize the treatment ABS, further details in the contact angle measurement section. Contact angle measurement and/or ink deposition began 30 minutes after treatment.

- $\mathrm{O}_{2}$ Plasma: Three treatment times (one, five, and ten minutes) of $\mathrm{O}_{2}$ exposure in a Plasma Etch PE-50 system. The five minute treatment is the primary treatment time for this study unless otherwise noted. Contact angle measurement and/or ink deposition began 30 minutes after treatment.

All of the ABS substrates were wiped with IPA one hour prior to the respective treatment or ink deposition. 


\section{Contact Angle Measurements}

Contact angle was measured as a potential indication of the wettability of the surfaces. Contact angle measurements were performed by using the sessile drop method with three $10 \mu \mathrm{L}$ droplets of DI water deposited onto each of three substrates for each surface treatment type to provide a minimum of 9 measurements per treatment. Illustrative droplet images are shown in Figure 5. Sand-blasting makes the surface more hydrophobic compared to untreated samples while flame and plasma treatments make the surface more hydrophilic. A decrease in contact angle on a smooth surface shows the surface energy is increasing and the surface chemistry is changing by eliminating organic contaminants, oxidizing/activating the surface, or perhaps even the creation of functional groups to produce a more hydrophilic surface. Prior research with X-ray photoelectron spectroscopy (XPS) shows flame treatment activates polymer surfaces with functional groups including hydroxyl, carbonyl, and carboxyl groups [27-29] while $\mathrm{O}_{2}$ plasma activates different oxygen containing functional groups including carboxyl, carbonyl, phenolic, hydroxyl, and aldehyde groups [30-32].

Flame treatment was performed by mounting a Dremel micro-pen butane torch mounted into a 3D motion system. The torch was translated over the substrate in a serpentine pattern with 5 passes and a $3 \mathrm{~mm}$ step-over between each pass while operating at its minimum setting. The paths were designed to travel past the edge of the substrate so that different dwell times during step-over would not create differential heating at the edges. The optimal conditions for flame treating were found by varying the speed (v) and treating distance (d) while measuring the resulting contact angle.

The minimum contact angle was achieved at $89 \mathrm{~mm}$ of treating distance from the flame tool spark arrestor to the surface of the substrates with a speed of $43 \mathrm{~mm} / \mathrm{s}$, as shown by the valley in 
Figure 6. These conditions were applied to five ABS substrates each with three water droplets to find the average contact angle of $70^{\circ}$, as represented in Figure 5. The results found here may not be a global optimum as further research suggested a much smaller treating distance may provide better treatment [33]. However, the speed would need to be much greater at closer treating distances and the 3D motion system used in this work was already approaching the upper speed limit of the motion system.

\section{Profilometry}

Substrate profiles were measured to detect surface topology changes due to the surface treatments. The surface topography of the substrates was characterized by using a Veeco Dektak 150 profilometer. Profilometry specifications include: a $5 \mu \mathrm{m}$ radius tip for the contact stylus, 3 $\mathrm{mg}$ of contact force, and a spatial resolution of $8 \mathrm{~nm}$ and $0.694 \mu \mathrm{m}$ in the vertical roughness and horizontal scan directions, respectively. Three scans of $12.5 \mathrm{~mm}$ each in 60 seconds were recorded for three substrates of each surface treatment subset. All specimens were measured for the sand-blasted group. The average $\left(\mathrm{R}_{\mathrm{a}}\right)$ and RMS $\left(\mathrm{R}_{\mathrm{q}}\right)$ surface roughness were recorded for each scan and averaged for an overall average and RMS roughness. A cut-off length of $3.5 \mathrm{~mm}$ was utilized to attenuate any low frequency "waviness" of the substrates. Table 1 summarizes measurements of the treated surfaces. Sand-blasting significantly increases the surface roughness of the ABS substrates while both chemical treatments (flame and plasma) show an insignificant change. 


\section{Results}

\section{Surface Treatment Study}

The strength of the adhesive/substrate bonds were found by sandwiching the adhesive between two ABS substrates in a conventional single lap shear joint with the same procedures in the single lap shear fabrication section. Figure 7 and Table 2 show the adhesive strength of the epoxy is $\sim 2.6 \mathrm{MPa}$ with mixed failure while the cyanoacrylate sandwiches failed via tensile failure of the substrate at an estimated substrate stress of $31 \mathrm{MPa}$, which is in the tensile strength range of $\mathrm{ABS}[34,35]$. The equivalent shear stress at substrate failure was approximately $4 \mathrm{MPa}$. The substrate-conductive ink interface was then evaluated with all of the surface treatments described above and summarized in Table 2/Figure 7. Overall, the failure modes match well for the epoxy and cyanoacrylate with the various surface treatments. This suggests the failure at the substrate-ink interface is independent of the adhesives utilized in this work.

Untreated ABS/CB028/adhesive single lap shear samples show 1.8 - 1.9 MPa of interfacial shear strength with mostly adhesive failure (Figure 7/Table 2). Surface treatments on the other hand have a profound effect on the interfacial shear strengths and adhesive failure modes of the CB028 conductive ink. Sand-blasting significantly increases the interfacial strength of ABS and CB028 by a factor of $\sim 1.8 \mathrm{x}$ and alters the adhesive failure mode to the more desired cohesive failure (Table 2). The sand-blasted surface features allow mechanical anchoring of the conductive ink due to increasing friction in the shear direction and also increasing the bonding area from the additional surface area. Flame treatment shows approximately $25 \%$ increase for interfacial shear strength of the epoxy adhesive but no change for the cyanoacrylate adhesive set. However, in both cases, the failure mode changed to mixed failure. This suggests there may be some improvement from flame treatment but it may be non-uniform or unpredictable with an 
inexpensive torch. Conversely, Figure 7 and Table 2 show the $\mathrm{O}_{2}$ plasma treatment increased the interfacial shear strength of CB028 and ABS by approximately $25 \%$ and alters the adhesive failure mode to cohesive failure for both adhesives.

Figure 8 shows representative adhesive failure surfaces. The light colored particles are silver from remaining $\mathrm{CB} 028$ conductive ink while dark regions are ABS substrate. The untreated samples in Figure 8a have very little silver particles remaining suggesting an adhesive failure mode. Figure $8 \mathrm{~b}$ shows the mixed failure pertaining to the flame treated samples having some regions with high concentrations of silver. The sand-blasted and plasma treated fracture surfaces of Figure $8 \mathrm{c}$ show lightly colored silver particles coat most of the ABS substrate indicating a cohesive failure mode. These conclusions were confirmed by measuring the average silver content using energy dispersive spectroscopy (EDS). Measured silver contents are included in the bottom of each SEM image of Figure 8.

\section{Plasma Treatment Study}

Figure 9a shows that a one, five, and ten minute plasma treatments have equivalent shear strength. An equivalent one minute plasma treatment is encouraging since an equivalent shear strength can be achieved with a much shorter treatment time. Figure $9 \mathrm{~b}$ shows the contact angle has reached a plateau after about one minute of plasma treatment, which indicates contact angle measurements can be an effective measurement to ensure a surface has been treated without having to perform shear testing. Furthermore, when conductive ink is deposited on the matte side of the ABS and plasma treated, the shear strength is significantly reduced with adhesive failure as opposed to cohesive as seen in Figure 9a. As a rule of thumb, the surface finish of a sheet of material should first be evaluated for adhesion when it varies on the opposite sides of the material. 
The five minute plasma treatment time was utilized to examine both the effect of the adhesive used and the surface finish (gloss versus matte) since it was the intermediate treatment level. The contact angle study of Figure $9 \mathrm{~b}$ shows that the plasma treatment already activates the surface after one minute of treatment. Additionally, the mechanical strength of the plasma treatment is independent of the adhesive used; therefore, the mechanical response at one and ten minutes of plasma treatment should be equivalent using epoxy as the adhesive or reduced when depositing conductive ink on the matte side of the ABS.

\section{Printed ABS Single Lap Shear Testing}

Table 3 and Figure 10 show the printed ABS substrates have $\sim 30 \%$ more shear strength than the smooth untreated ABS substrates. The conductive ink (CB028) failed cohesively on the printed substrates compared to adhesive failure on the smooth untreated ABS substrates. These benefits are likely due to the increased surface area for bonding of the conductive ink while the recesses in the undulated features create mechanical anchoring sites for added strength. In a prior work, electrical performance has been shown to be dependent on extrusion orientation [19]. The equivalent shear strength of the printed substrates allows greater design freedom of printed electronics as the conductive elements do not have to align with a certain extrusion orientation to maximize strength but can be selected based on achieving maximum electrical performance. Additionally, Figure 10 shows that the tensile strength of a notched printed ABS sample and the ultimate tensile strength (UTS) of printed ABS in the weakest orientation (z-axis) [20] is about $3 \mathrm{x}$ and $8 \mathrm{x}$ greater than the shear strengths of the conductive inks spread onto printed ABS substrates, respectively. This shows that the conductive ink will likely be the locus of failure. Therefore, conductive elements should be placed in areas of low stress to minimize the potential failure for printed electronic devices. Development of electronic materials and/or processing 
methods with improved interfacial strength could significantly increase design freedom and enhance system performance.

\section{Discussion}

In this work, single lap shear testing was demonstrated for assessing the bonding of a conductive ink to its substrate. The role of the adhesive connecting the conductive ink to a second substrate was evaluated by comparing two different adhesives while maintaining other variables constant besides the surface treatments. In general, the two adhesives utilized (Pelco epoxy and cyanoacrylate) match well for the various surface treatments, as evident in Figure 7. This reinforces that the failures within the ink or ink/substrate interface are independent of the adhesive and that the adhesive is not altering the properties of the ink.

Of the two adhesives tested in this work, the cyanoacrylate may be preferred. The cyanoacrylate is more economical than the epoxy and doesn't require mixing, but more importantly, the cyanoacrylate sets within minutes as compared to several hours for the epoxy. In a work by Lin [36] it was also found that cyanoacrylate was the most convenient and satisfactory adhesive to apply when single lap shear testing vacuum deposited metallic films (gold, aluminum, and copper) on glass and magnesium oxide substrates. No penetration of the cyanoacrylate into the films was detectable by electron diffraction.

In regards to the surface treatments, sand-blasting shows a significant increase in the interfacial strength. However, sand-blasting is the least attractive surface treatment for printed electronics. In printed electronics, the conductive materials are deposited in an additive fashion allowing electronics to be printed onto interior surfaces or embedded within a component in a layer-bylayer additive manufacturing process. These capabilities enable protection of design information, added space efficiency, and even wear protection that are not offered (or may be very difficult) 
without additive manufacturing processes. Sand-blasting would be very difficult to integrate into an additive manufacturing process as an intermediate step. It would likely have to be a separate enclosed chamber that the part could be translated to and sealed before blasting. The blasted component would still have to be cleaned afterwards. This adds significant complexity to the AM process. Also, the rough features of the sand-blasted components may effect electrical performance significantly by increasing the dissipative losses of radio frequency printed electronic devices [19, 37-40].

Fortunately, the surface roughness of printed substrates may achieve some of the same benefits of sandblasting. Conductive ink deposited on printed polymer substrates with undulated roughness shows $\sim 30 \%$ increase in interfacial shear strength and altered the adhesive failure mode to cohesive failure when comparing smooth untreated ABS substrates. Conductive inks deposited on extrusion $3 \mathrm{~d}$ printed ABS substrates with undulated roughness perpendicular to the applied force were hypothesized to have more mechanical interlocking and resistance to shear failure than those deposited parallel. However, no significant difference in shear strength was found between perpendicular and parallel extrusions. This may eliminate a trade-off between adhesion and electrical performance while depositing conductive inks onto extruded surfaces. The geometric freedom of extrusion or other AM processes could produce designed features or textures that could enhance adhesion of deposited conductive inks. A separate tool that scratched or knurled the surface could also produce adhesion promoting textures with mechanical interlocking features. These geometric effects could also be combined with chemical treatments. Chemical treatments can be readily integrated into a multi-tooled AM machine with the use of micro-pen flame torches or plasma pens. Flame treatment only shows a marginal improvement in adhesive strength with the parameters in this work. Higher temperature polymers may show 
more benefit from flame treatment as the treatment could be more intense without deforming the substrate. Modifications to the heating parameters could also increase the benefit while use of a torch with a forced continuous flow or a wider flame may increase treatment consistency. Plasma treatments of one, five, and ten minutes show equivalent shear strengths when deposited on the gloss side of the ABS substrates. This suggests that the shear strength increase has plateaued and perhaps a shorter treatment time could be used to achieve an equivalent shear strength. Furthermore, a combination of mechanical features and a chemical surface treatment could provide maximum adhesion with benefits from mechanical interlocking and surface chemistry changes. For instance, a knurling tool that is being torched as it is being rotated could provide a texturized surface with adhesion promoting surface chemistry changes.

Conductive ink thickness in many printed electronics is less than the $50 \mu \mathrm{m}$ used in this work but Lin [36] also found that interfacial strength was virtually independent of the metallic $(\mathrm{Au}, \mathrm{Cu}$, and Al) film thickness between 0.05 to $40 \mu \mathrm{m}$ for vacuum deposited films. Micro-dispensed conductive inks tend to have a higher density of metallic particles that collect towards the bottom of the cross-section and would be characteristic regardless of thickness, which suggests printed electronics with conductive ink thickness $<50 \mu \mathrm{m}$ may behave similarly if the cross-sectional particle distribution was similar [41]. More recent work by Gleich, et al. [42] and Silva et al. [43] shows that thinner coatings actually have less interfacial stress at the interfaces of the coating and substrates; therefore, thinner coatings of conductive inks with $<50 \mu \mathrm{m}$ in thickness should behave similarly or have added strength.

\section{Conclusions}

The qualitative adhesion test method of cross-hatch scratch testing did not render differences in adhesion when varying the surface treatment prior to depositing conductive ink on $\mathrm{ABS}$ 
substrates in this work. Therefore, the quantitative adhesion test method of single lap shear testing was pursued as a more aggressive adhesion test that can be effective for adhesion evaluation in printed electronics applications.

Surface treatments show potential to increase the interfacial shear strength of conductive inks and alter the adhesion failure mode. Untreated smooth ABS shows mostly adhesive failure with relatively small amounts of silver particles from the CB028 conductive ink remaining on the fracture surface after shearing. Chemical surface treatments including plasma and flame show $\sim 25 \%$ increase in interfacial shear strength and alter the adhesive failure mode to the preferred cohesive for most cases. Both chemical treatments have the potential to be integrated into a multi-tooled AM system with plasma or flame pens for in-line treatment prior to conductive ink deposition. Alternatively, the mechanical surface treatment of sand-blasting shows about a $80 \%$ increase in the interfacial strength while also altering the failure mode from adhesive to cohesive failure, however, it cannot be readily adapted into an in-line AM process as easily as the chemical treatments.

While sandblasting is difficult to incorporate into a process, the geometric freedom of AM processes can produce designed surface features or textures that could promote mechanical interlocking and an increase in adhesion strength in a similar fashion to sand-blasted surfaces. For instance, printed extruded ABS substrates increase the interfacial strength by $\sim 30 \%$ and alter the adhesive failure mode to cohesive failure independent of extrusion orientation, which allows conductive elements to be designed based on preferred orientation for electrical performance. These features could be combined with chemical treatments for further improvement. 


\section{References}

1. Haria, R. How 3D Printing has Changed Dentistry, A Billion Dollar Opportunity. Medical \& Dental 2017; Available from: https://3dprintingindustry.com/news/3d-printing-impact-ondentistry-121284/.

2. Kellner, T. World's First Plant to Print Jet Engine Nozzles in Mass Production. GE Reports 2014; Available from: https:/www.ge.com/reports/post/91763815095/worlds-first-plant-to-printjet-engine-nozzles-in/.

3. Kellner, T. An Epiphany of Disruption: GE Additive Chief Explains How 3D Printing Will Upend Manufacturing. GE Reports 2017; Available from: https://www.ge.com/reports/epiphanydisruption-ge-additive-chief-explains-3d-printing-will-upend-manufacturing/.

4. McCue, T.J. 3D Printing Moves Align Technology Toward \$1.3 Billion in Sales. 2017; Available from: https:/www.forbes.com/sites/tjmccue/2017/09/14/3d-printing-moves-align-technologytoward-1-3-billion-in-sales/\#1a7e999a5378.

5. Church, K.H., et al. Advanced Printing for Microelectronic Packaging. in IPC APEX EXPO Conference Proceedings.

6. Rojas-Nastrucci, E.A., R.A. Ramirez, and T.M. Weller. Direct digital manufacturing of mm-wave vertical interconnects. in 2018 IEEE 19th Wireless and Microwave Technology Conference (WAMICON). 2018.

7. Rojas-Nastrucci, E.A., et al. Laser enhanced direct print additive manufacturing for mm-wave components and packaging. in 2017 International Conference on Electromagnetics in Advanced Applications (ICEAA). 2017.

8. Ramirez, R., E.A. Rojas-Nastrucci, and T. Weller, Laser-Assisted Additive Manufacturing of mmWave Lumped Passive Elements. Vol. PP. 2018. 1-10.

9. Schrand, A., Additive Manufacturing: From Form to Function. Strategic Studies Quarterly, 2016. 10(3): p. 74-90.

10. Louis, M.J., T. Seymour, and J. Joyce, 3D oppportunity in the Department of Defense: Additive manufacturing fires up. A Deloitte series on additive manufacturing. 2014: Deloitte University Press.

11. Neff, C., et al., A fundamental study of printed ink resiliency for harsh mechanical and thermal environmental applications. Additive Manufacturing, 2018. 20: p. 156-163.

12. Lacombe, R., Adhesion Measurement Methods: Theory and Practice. 2005, Boca Raton, FL: CRC Press.

13. Adhesion Measurements of Thin Films, Thick Films, and Bulk Coatings. American Society for Testing and Materials (ASTM) STP 640, ed. K.L. Mittal. 1978.

14. Abbott, S., Adhesion Science: Principles and Practice. 2015, Lancaster, Pennsylvania: DEStech Publications, Inc.

15. Moroni, F., F. Musiari, and A. Pirondi, Influence of laser ablation-induced surface topology on the mechanical behaviour of aluminium bonded joints. Proceedings of the Institution of Mechanical Engineers, Part L: Journal of Materials: Design and Applications, 2018. 233(3): p. 505-520.

16. Spaggiari, A. and E. Dragoni, Effect of Mechanical Surface Treatment on the Static Strength of Adhesive Lap Joints. The Journal of Adhesion, 2013. 89(9): p. 677-696.

17. Mittal, K.L., Adhesion Measurement of Thin Films. Electrocomponent Science and Technology, 1976. 3: p. 21-42.

18. ASTM, D 3163 - 01 Standard Test Method for Determining Strength of Adhesively Bonded Rigid Plastic Lap-Shear Joints in Shear by Tension Loading.

19. Neff, C., et al., Thermal and Vapor Smoothing of Thermoplastic for Reduced Surface Roughness of Additive Manufactured RF Electronics. IEEE Transactions on Components, Packaging, and Manufacturing Technology, 2019. 
20. Neff, C., M. Trapuzzano, and N.B. Crane, Impact of Vapor Polishing on Surface Quality and Mechanical Properties of Extruded ABS. Rapid Prototyping Journal, 2018. 24(2): p. 501-508.

21. Hallman, L., et al., The improvement of adhesive properties of PEEK through different pretreatments. Applied Surface Science, 2012. 258: p. 7213-7218.

22. Hegemann, D., H. Brunner, and C. Oehr, Plasma treatment of polymers for surface and adhesion improvement. Nuclear Instruments and Methods in Physics Research Section B: Beam Interactions with Materials and Atoms, 2003. 208: p. 281-286.

23. Mittal, K.L. and A. Pizzi, Adhesion Promotion Techniques. 1999, New York, USA: Marcel, Dekker, Inc. .

24. Schuelke, R., Mastering Plasma \& Flame Surface Treating Technologies to Improve Adhesion, in Antec. 2016: Indianapolis.

25. Schwitalla, A.D., et al., The impact of argon/oxygen low-pressure plasma on sher bond strength between a veneering composite and different PEEK materials. Dental Materials, 2017. 33: p. 990994.

26. Zhou, L., et al., Effect of different surface treatments and thermocycling on shear bond strength to polyetheretherketone. High Performance Polymers, 2016. 29(1): p. 87-93.

27. Garbassi, F., et al., Surface effect of flame treatments on polypropylene. Journal of Materials Science, 1987. 22(4): p. 1450-1456.

28. Dillard, J.G., et al., Surface Properties and Adhesion of Flame Treated Sheet Molded Composite (SMC). The Journal of Adhesion, 1988. 26(2-3): p. 181-198.

29. Briggs, D., D.M. Brewis, and M.B. Konieczo, X-ray photoelectron spectroscopy studies of polymer surfaces. Journal of Materials Science, 1976. 11(7): p. 1270-1277.

30. Pittman, C., et al., Oxygen plasma and isobutylene plasma treatments of carbon fibers: Determination of surface functionality and effects on composite properties. Vol. 36. 1998. 25-37.

31. Comyn, J., et al., Plasma-treatment of polyetheretherketone (PEEK) for adhesive bonding. International Journal of Adhesion and Adhesives, 1996. 16(2): p. 97-104.

32. Liu, C., et al., Surface modification of PTFE by plasma treatment. Surface Engineering, 2000. 16(3): p. 215-217.

33. Farris, S., et al., The fundamentals of flame treatment for the surface activation of polyolefin polymers - A review. Polymers, 2010. 51(3591-3605).

34. Jr., W.D.C. and D. Rethwisch, Materials Science and Engineering An Introdution. 8th ed. 2010: John Wiley \& Sons, Inc. .

35. Ashby, M.F., Materials and the Environment. 2013: Elsevier, Inc.

36. Lin, D.S., The adhesion of metal films to glass and magnesium oxide in tangential shear. Journal of Physics D: Applied Physics, 1971. 4(12): p. 1977-1990.

37. Edwards, T.C. and M.B. Steer, Foundations for Microstrip Circuit Design. 4th ed. 2016: John Wiley \& Sons.

38. Jr., S.P.M., Effect of sirface roughness on eddy current losses at microwave frequencies. Journal of Applied Physics, 1949. 20(352).

39. Ketterl, T.P., et al., A 2.45 GHz Phased Array Antenna Unit Cell Fabricated Using 3-D MultiLayer Direct Digital Manufacturing. IEEE Transactions on Microwave Theory and Techniques, 2015. 63(12): p. 4382-4394.

40. Matsushima, A. and K. Nakata, Power Loss and Local Surface Impedance Associated with Conducting Rough Interfaces. Electronics and Communications in Japan (Part 2:Electronics), 2006. 89(1).

41. Church, K.H., et al., Multimaterial and multilayer direct digital manufacturing of $3 D$ structural microwave electronics. Proceedings of the IEEE, 2017. 105(4): p. 688-701.

42. Gleich, D.M., M.J.L.V. Tooren, and A. Beukers, Analysis and evaluation of bondline thickness effects on failure load in adhesively bonded structures. Journal of Adhesion Science and Technology, 2001. 15(9): p. 1091-1101. 
43. Silva, L.F.M.d., et al., Effect of Adhesive Type and Thickness on the Lap Shear Strength. The Journal of Adhesion, 2006. 82(11): p. 1091-1115. 


\section{List of Tables}

Table 1: Average (Ra) and root mean square $(\mathrm{Rq})$ surface roughness measurements.

\begin{tabular}{lcc}
\hline Surface Treatment & Ra $(\boldsymbol{\mu m})$ & Rq $(\boldsymbol{\mu m})$ \\
\hline Untreated & $0.12 \pm 0.07$ & $0.25 \pm 0.19$ \\
Sand-blasted & $5.11 \pm 0.22$ & $6.65 \pm 0.32$ \\
Flame & $0.07 \pm 0.03$ & $0.11 \pm 0.07$ \\
$\mathrm{O}_{2}$ Plasma & $0.09 \pm 0.04$ & $0.13 \pm 0.05$ \\
\hline
\end{tabular}

Table 2: Single lap shear numerical data with adhesive failure modes.

\begin{tabular}{lccc}
\hline Surface Treatment & $\begin{array}{c}\text { Epoxy } \\
\text { Avg. Stress (MPa) }\end{array}$ & $\begin{array}{c}\text { Cyanoacrylate } \\
\text { Avg. Stress (MPa) }\end{array}$ & Failure Mode \\
\hline Adhesive Sandwiches & $2.56 \pm 0.443$ & $3.97 \pm 0.02$ & Mixed/Substrate \\
Untreated & $1.89 \pm 0.34$ & $1.77 \pm 0.31$ & Mostly adhesive \\
Sand-blasted & $3.35 \pm 0.44$ & $3.29 \pm 0.45$ & Cohesive \\
Flame & $2.62 \pm 0.27$ & $1.86 \pm 0.28$ & Mixed \\
$\mathrm{O}_{2}$ Plasma (5 min.) & $2.56 \pm 0.18$ & $2.69 \pm 0.38$ & Cohesive \\
\hline
\end{tabular}

Table 3: Comparison of shear strengths and adhesive failure modes of smooth and printed single lap shear ABS substrates to tensile strengths of printed ABS.

\begin{tabular}{lcc}
\hline Sample Type & Shear Strength (MPa) & Failure Mode \\
\hline Untreated Smooth ABS & $1.77 \pm 0.31$ & Mostly Adhesive \\
Printed Parallel ABS & $2.39 \pm 0.47$ & Cohesive \\
Printed Perpendicular ABS & $2.55 \pm 0.32$ & Cohesive \\
Printed ABS Strength with Stress Concentration & $6.46 \pm 0.26$ & Tensile \\
Printed ABS z-axis (UTS) [20] & $15.32 \pm 1.78$ & Tensile \\
\hline
\end{tabular}




\section{List of Figures}

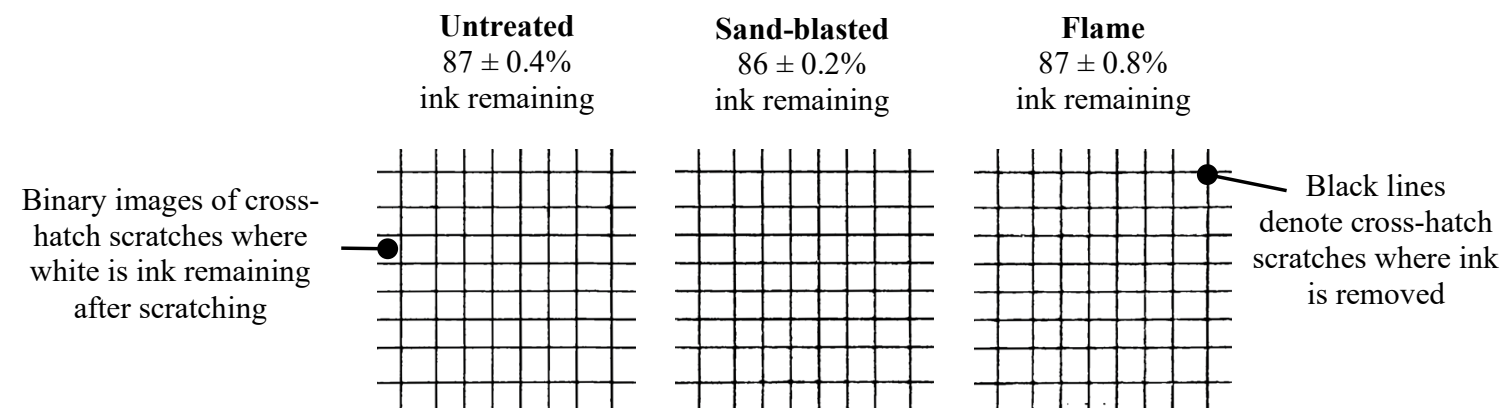

Figure 1: Photograph of cross-hatch scratches of CB028 conductive ink deposited on ABS substrates. Note the very similar amount of ink remaining regardless of surface treatment that indicates the test cannot resolve adhesion differences. Note: poor adhesion would be indicated by large black areas due to significant ink being removed from the cross-hatch scratches. The images above show the ink is still intact even after cross-hatch scratching and adequate adhesion is achieved regardless of surface treatment of the ABS, which provides motivation for a more aggressive, quantitative adhesion measurement.

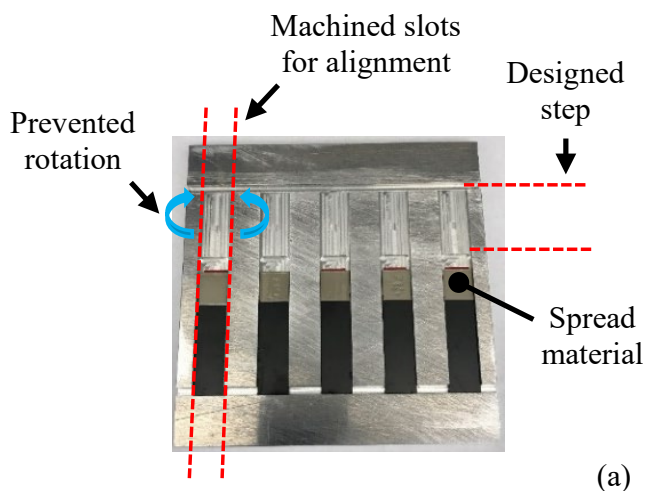

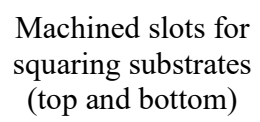

Machined slots for squaring substrates (top and bottom)

Machined fixture (dashed lines) with designed

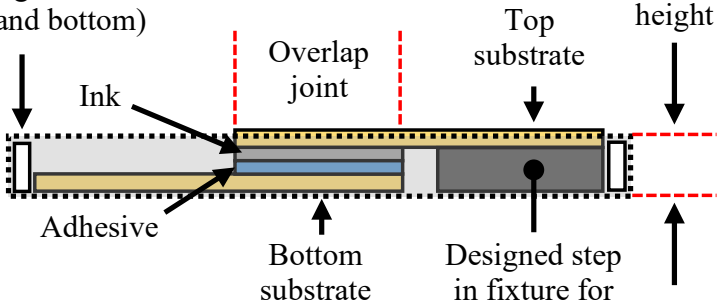

support

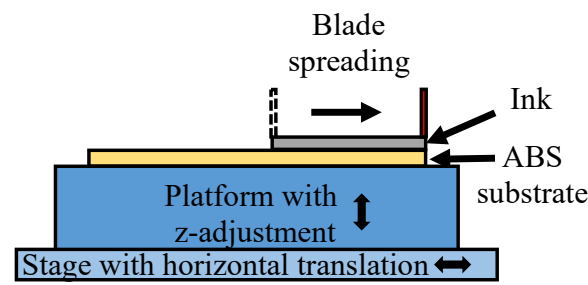

(c)

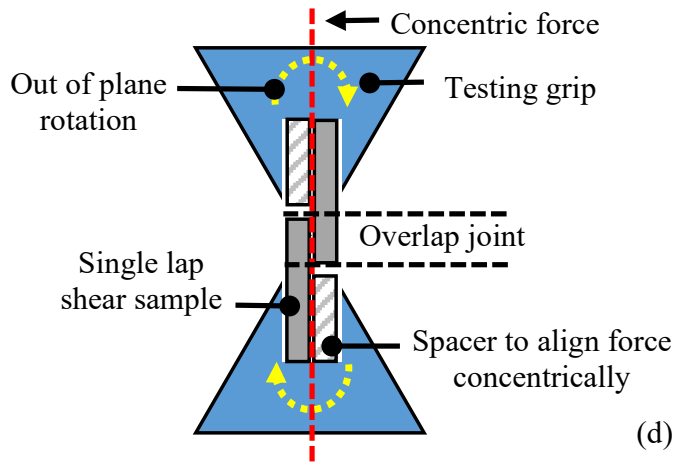

(d) 
Figure 2: Single lap shear fabrication and testing. Designed machined fixture for repeatable fabrication of single lap shear samples with (a) top view and (b) side view with the machine fixture as a dashed outline. Spreading mechanism for repeatable thickness of both conductive ink and adhesive (c). Diagram of single lap shear testing with spacers the same thickness as the single lap shear substrates to align the force concentrically as the upper testing grip moves vertically to induce shear failure of the sample (d).

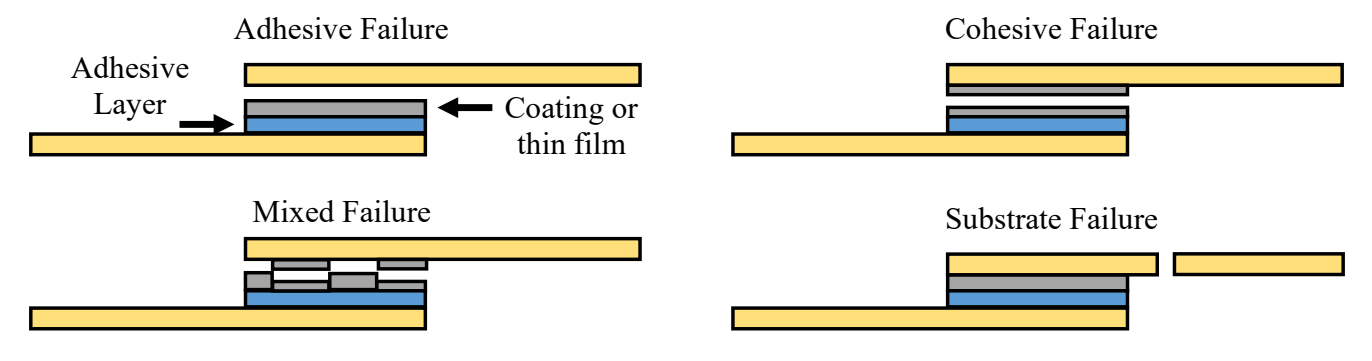

Figure 3: Adhesive failure modes with single lap shear tests. Note the adhesive layer shows the adhesive has the purpose of attaching the coating or thin film (CB028 conductive ink in this work but can be another coating in different works) to the bottom substrate.

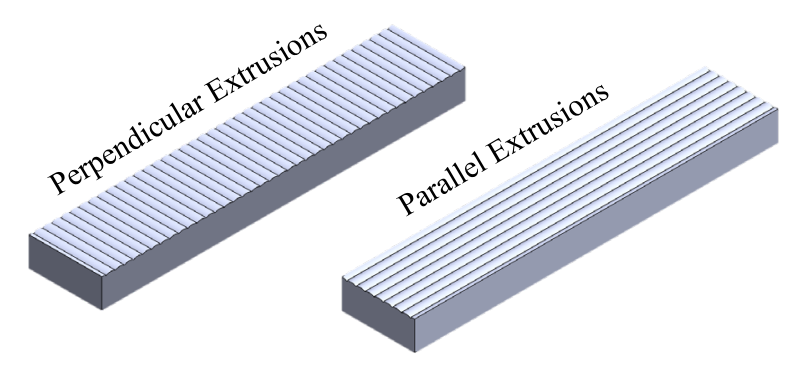

Figure 4: Printed single lap shear substrates with perpendicular and parallel extrusions relative to the long axis of the substrate to evaluate the shear strength of printed substrates and to evaluate the adhesion dependence on extrusion orientation.

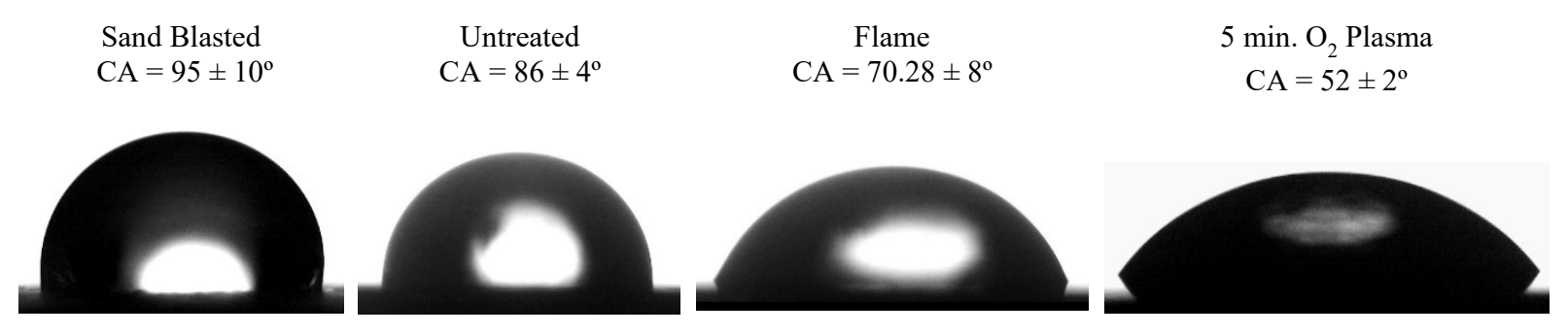


Figure 5: Average contact angle measurements for the respective surface treatments with a representative image of the contact angle.
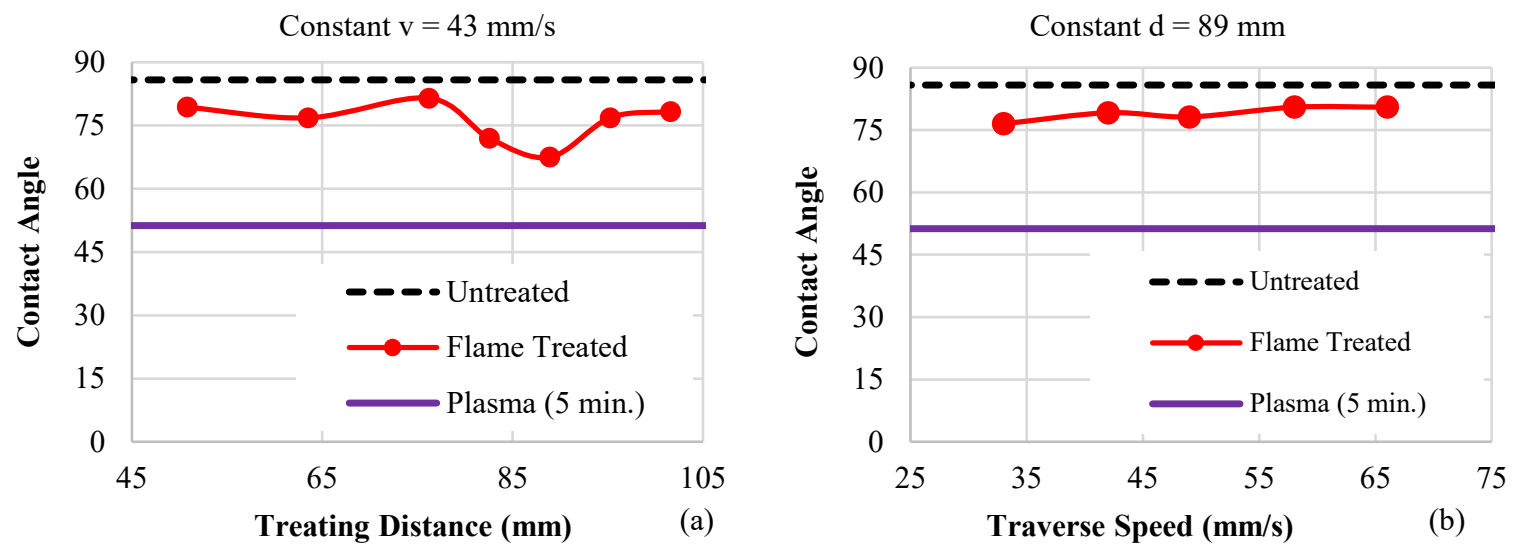

Figure 6: Flame treatment preliminary optimization for speed (v) and treating distance (d) to minimize contact angle: (a) constant speed while varying the treating distance and (b) constant treating distance while varying the traverse speed of the flame torch.

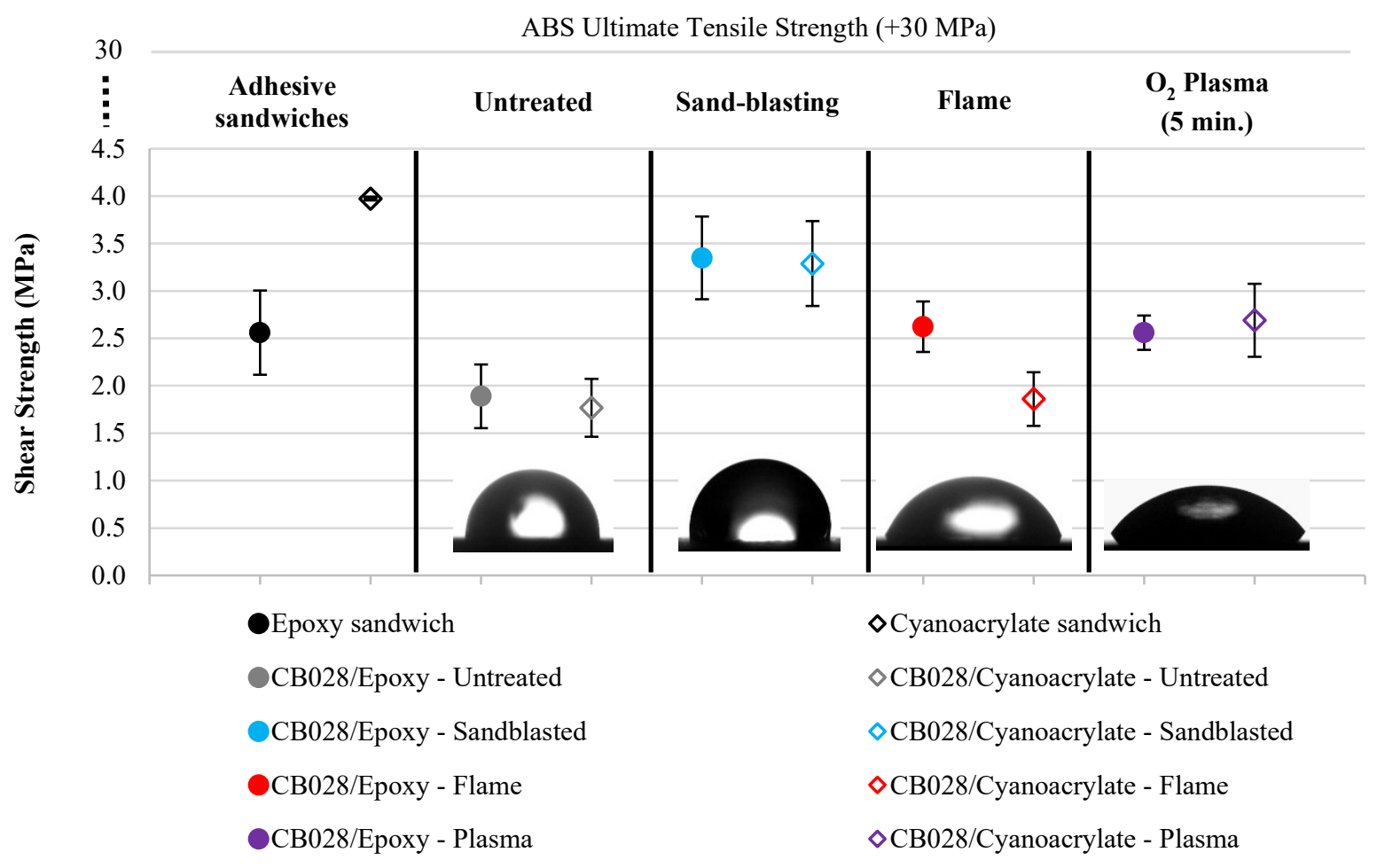

Figure 7: Single lap shear testing results. 

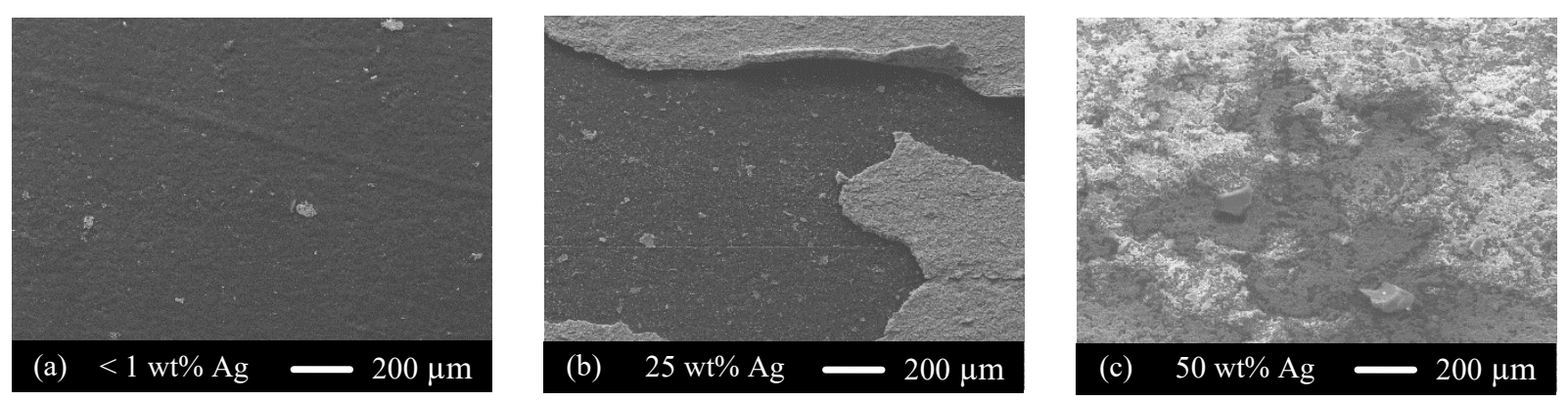

Figure 8: SEM images of fracture surfaces showing a representative of the adhesive failure modes: (a) adhesive (very little silver particles remaining), (b) mixed (some areas of high and low concentration of silver particles), and (c) cohesive (high concentration of silver particles coating the fracture surface). Note the silver (Ag) weight \% from EDS analysis is included at the bottom of each SEM image.
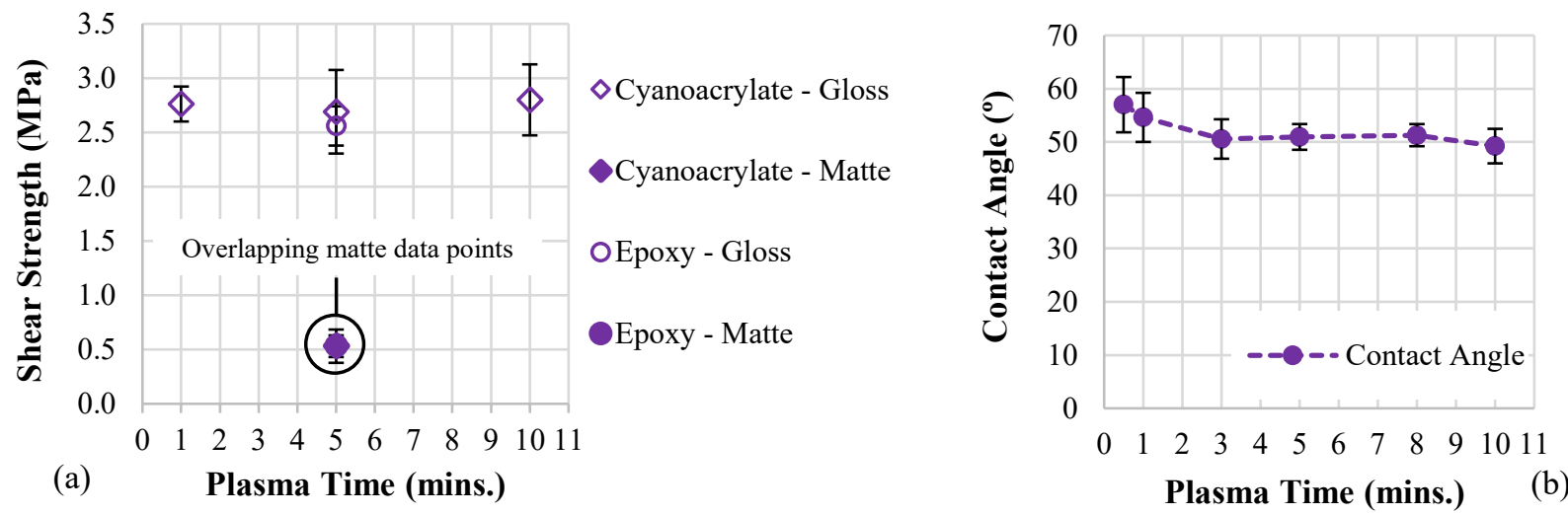

Figure 9: (a) Shear strength for varying the plasma treatment time and the surface finish of the ABS. Note the shear strength is independent of the plasma treatment when $\mathrm{CB028}$ is deposited on the gloss side of the ABS but the shear strength is much less when deposited on the matte side of the ABS for the same treatment time and adhesive. (b) Contact angle versus plasma treatment time on the gloss side of the ABS. Note the contact angle seems to have reached a plateau after one minute of plasma treatment. 


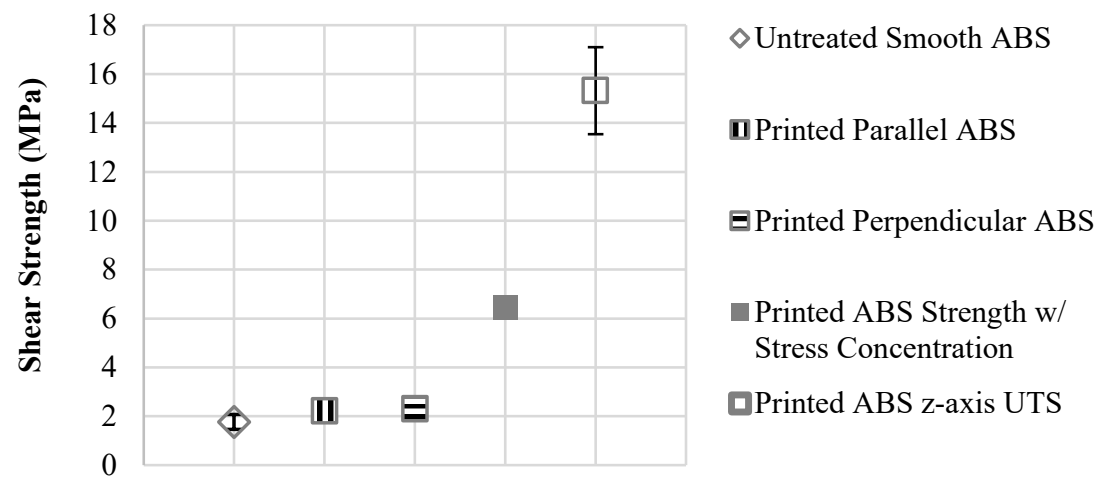

Figure 10: Shear strengths of printed samples. Note the printed single lap shear ABS substrates with parallel and perpendicular extrusions have $\sim 30 \%$ increased shear strength when comparing the smooth ABS single lap shear substrates. Also, the single lap shear samples with conductive ink have much less strength than printed ABS with a stress concentration and tensile strength in the z-axis. 